\title{
Plasma Material Interaction in Tokamak: the Contribution of WEST and of Laboratory Studies
}

\author{
Christian GRISOLIA ${ }^{1}$ and the Tore Supra Team \\ ${ }^{1}$ CEA-DSM-IRFM, Service Intégration Plasma Paroi, SIPP (Cadarache, France)
}

In 2016, the WEST tokamak will be in operation and the first plasmas realized. This setup is a machine with a full W actively cooled plasma facing components (PFCs). Depending on the heat loads that must be sustained by the WEST PFCs [1], some of them will be composed of massive tungsten welded on heat sink and other of W coatings on carbon tiles (see Fig. 1).

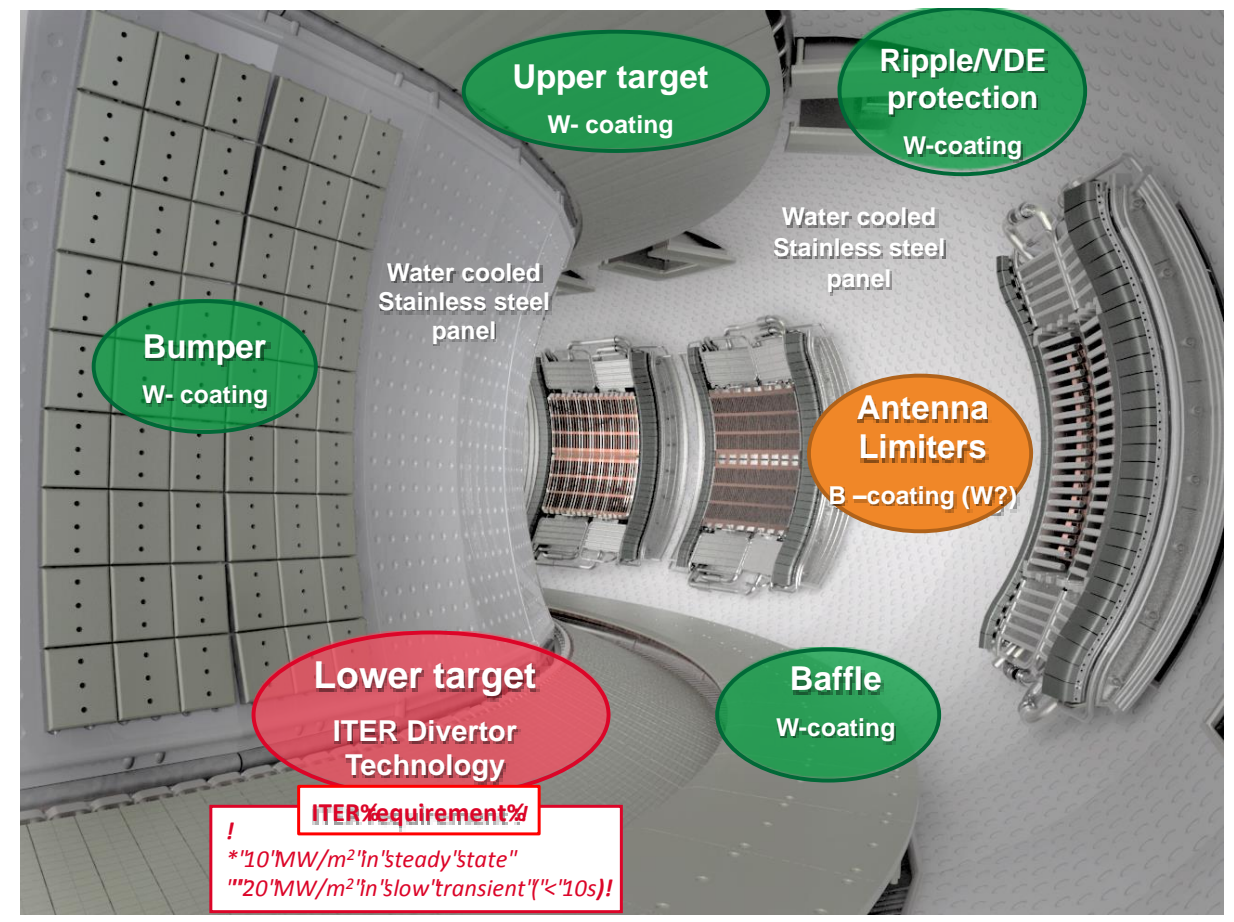

Fig. 1: Summary of the WEST Plasma Facing Component in its final configuration.

During plasma operation, these W PFCs are submitted to harsh heat loads and plasma out flow [2]. The PFCs placed at the lower target of the machine (see figure 1) are ITER type actively cooled components and will be submitted in WEST to heat loads from 10 to $20 \mathrm{MW}$ and to particles flux densities up to $10^{23}$ particles $\mathrm{m}^{-2} \mathrm{~s}^{-1}$. The ITER technology used here will be described in the presentation as well as the one using coated materials. The comparison of the expected heat and particles loads expected in WEST and in ITER will be also compared.

Several main ITER issues can be studied in such a setup. How the materials evolve when submitted at so high flux? We will study this point and this topic will be described in the presentation.

The WEST can also be used to address one important open issue for ITER that is the deuterium/tritium trapping in massive and dust materials. 
A French consortium has been put in place to study at the laboratory scale deuterium and trapping in relevant massive and dusty material. The work-program of such project will be presented during the meeting with the first important results obtained in experimental results $[3,4]$. The modelling approach will be also described with some of the key results obtained on tungsten materials $[5,6,7]$. From existing and published results, the consequences of neutrons interaction on the tritium trapping in the ITER machine will be finally discussed.

\section{References}

[1] The WEST project: Testing ITER divertor high heat flux component technology in a steady state tokamak environment, J. Bucalossi et a., Fusion Engineering and Design 10/2014; 89(7-8):907912. DOI:10.1016/j.fusengdes.2014.01.062.

[2] WEST Physics Basis, C. Bourdelle et al., Nuclear Fusion 06/2015; 55(6):063017. DOI:10.1088/ 0029-5515/55/6/063017.

[3] Dynamic fuel retention in tokamak wall materials: An in situ laboratory study of deuterium release from polycrystalline tungsten at room temperature, R. Bisson, S. Markelj, O. Mourey, F. Ghiorghiu, K. Achkasov, J.-M. Layet, P. Roubin, G. Cartry, C. Grisolia, T. Angot J. Nucl. Mater. (2015), http://dx.doi.org/10.1016/j.jnucmat.2015.07.028.

[4] Tritium absorption and desorption in ITER relevant materials: comparative study of tungsten dust and massive samples, C. Grisolia, E. Hodille, J. Chene, S. Garcia-Argote, G. Pieters, A. ElKharbachi, L. Marchetti, F. Martin, F. Miserque, D. Vrel, M. Redolfi, V. Malard, G. Dinescu, T. Acsente, F. Gensdarmes, S. Peillon, B. Pegourié, B. Rousseau, Journal of Nuclear Materials, Volume 463, August 2015, pp. 885-888.

[5] Hydrogen diffusion and vacancies formation in tungsten: Densirty Functional Theory calculations and statistical models, N. Fernandez, y. Ferro and D. Kato, acta Materiala 94 (2015) 307-318.

[6] Macroscopic rate equation modeling of trapping/detrapping of hydrogen isotopes in tungsten materials, E.A. Hodille' X. Bonnin, R. Bisson, T. Angot, C.S. Becquart, J.M. Layet, C. Grisolia' accepted for publication, Nucl. Mater. (2015), http://dx.doi.org/10.1016/i.jnucmat.2015.06.041.

[7] Study of Hydrogen Isotopes behavior in tungsten by a multi trapping macroscopic rate equation model, E. A. Hodille, Y. Ferro, N. Fernandez, C. S. Becquart, T. Angot, J. M. Layet, R. Bisson, C. Grisolia, accepted for publication in Physica Scripta, 2015. 


\title{
Plasma material interaction in tokamak: the contribution of WEST and of laboratory studies
}

\author{
C Grisolia and TORE Supra team
}



the JET

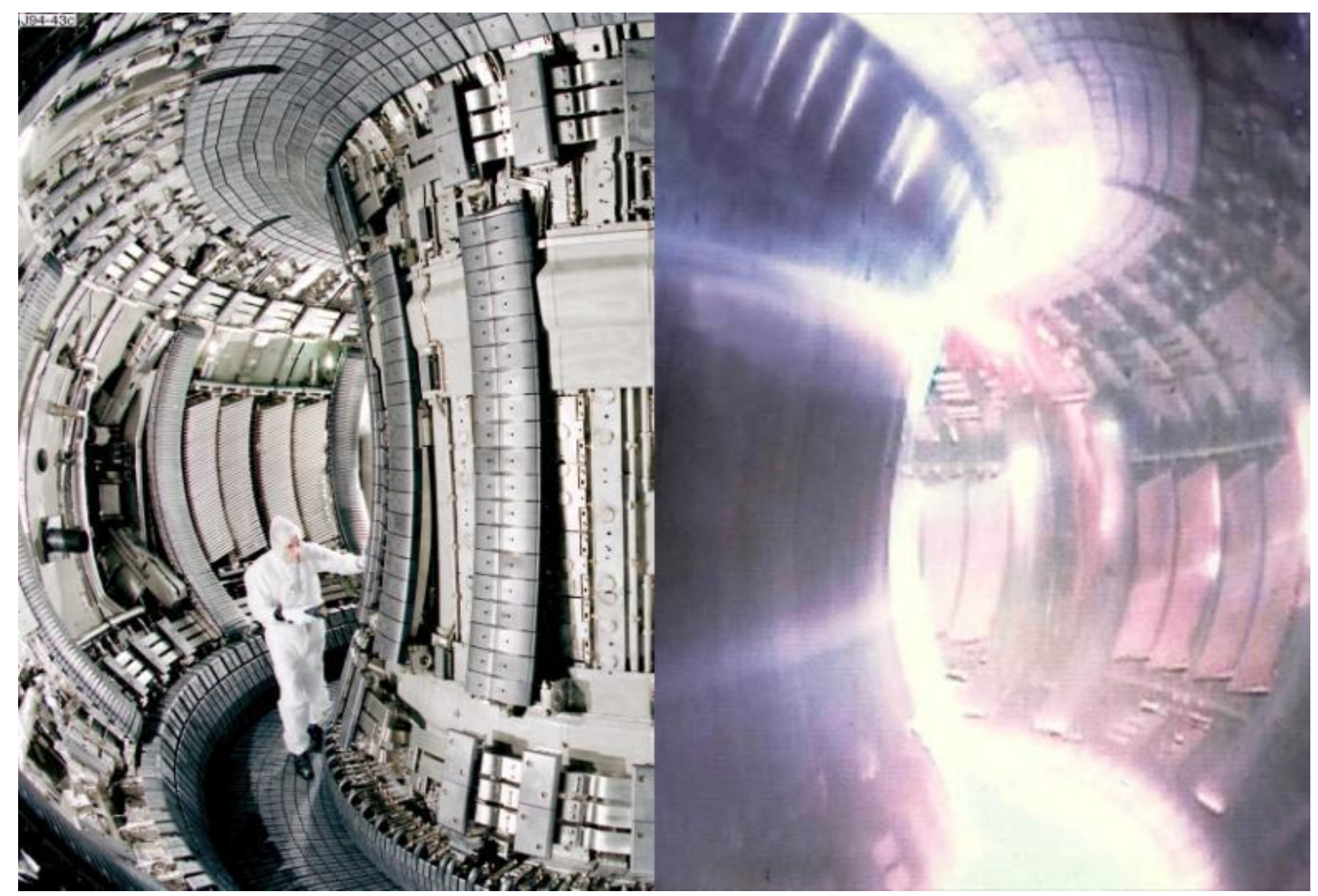

Largest machine in the world $\left(\mathrm{V}_{\text {plasma }} \sim 50 \mathrm{~m}^{3}\right.$ de plasma) T capability $\rightarrow$ achieved 16 MW of fusion power (1997) 


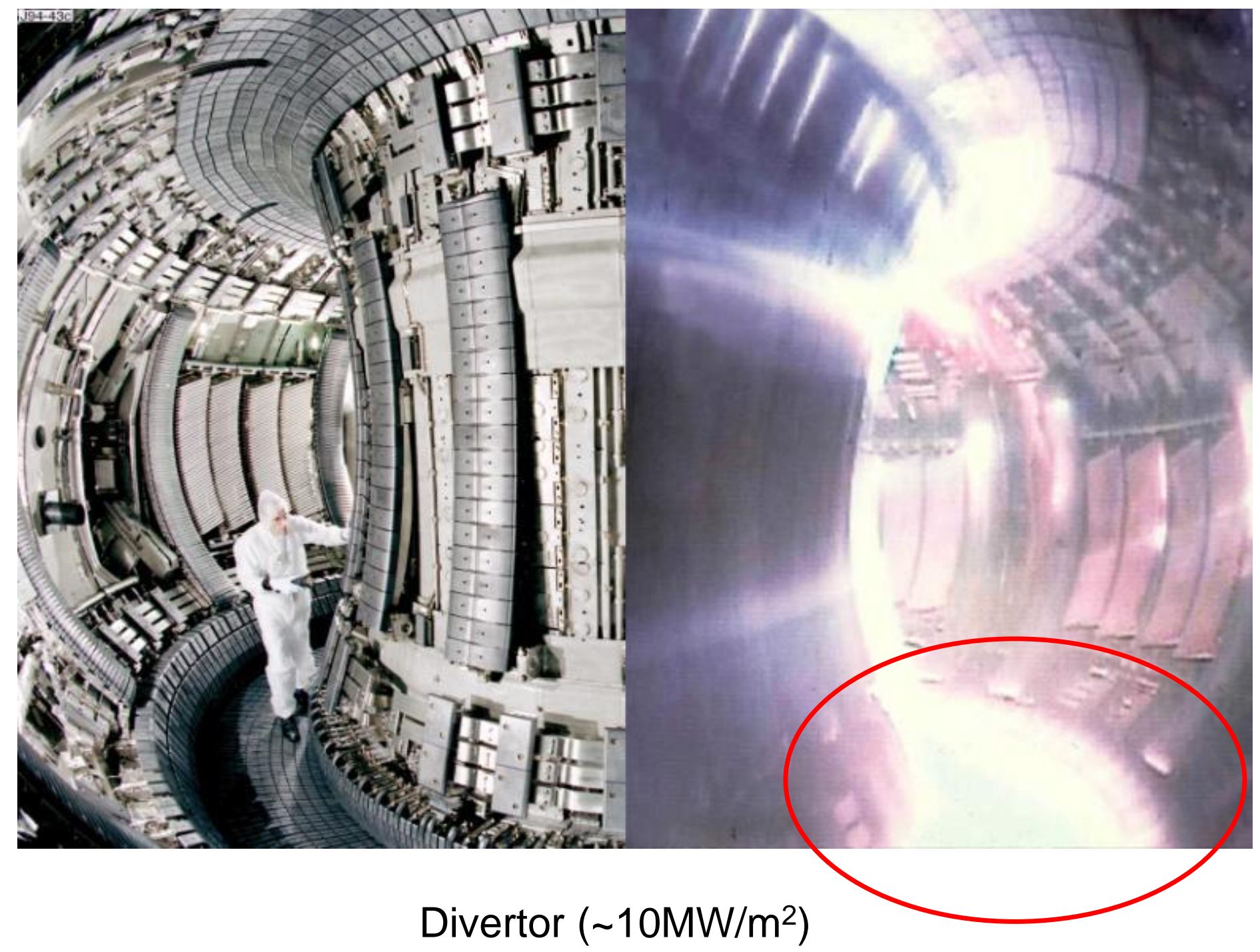

But non actively cooled Plasma Facing Units (PFU) $\rightarrow$ Limited performance (non steady state operation) 


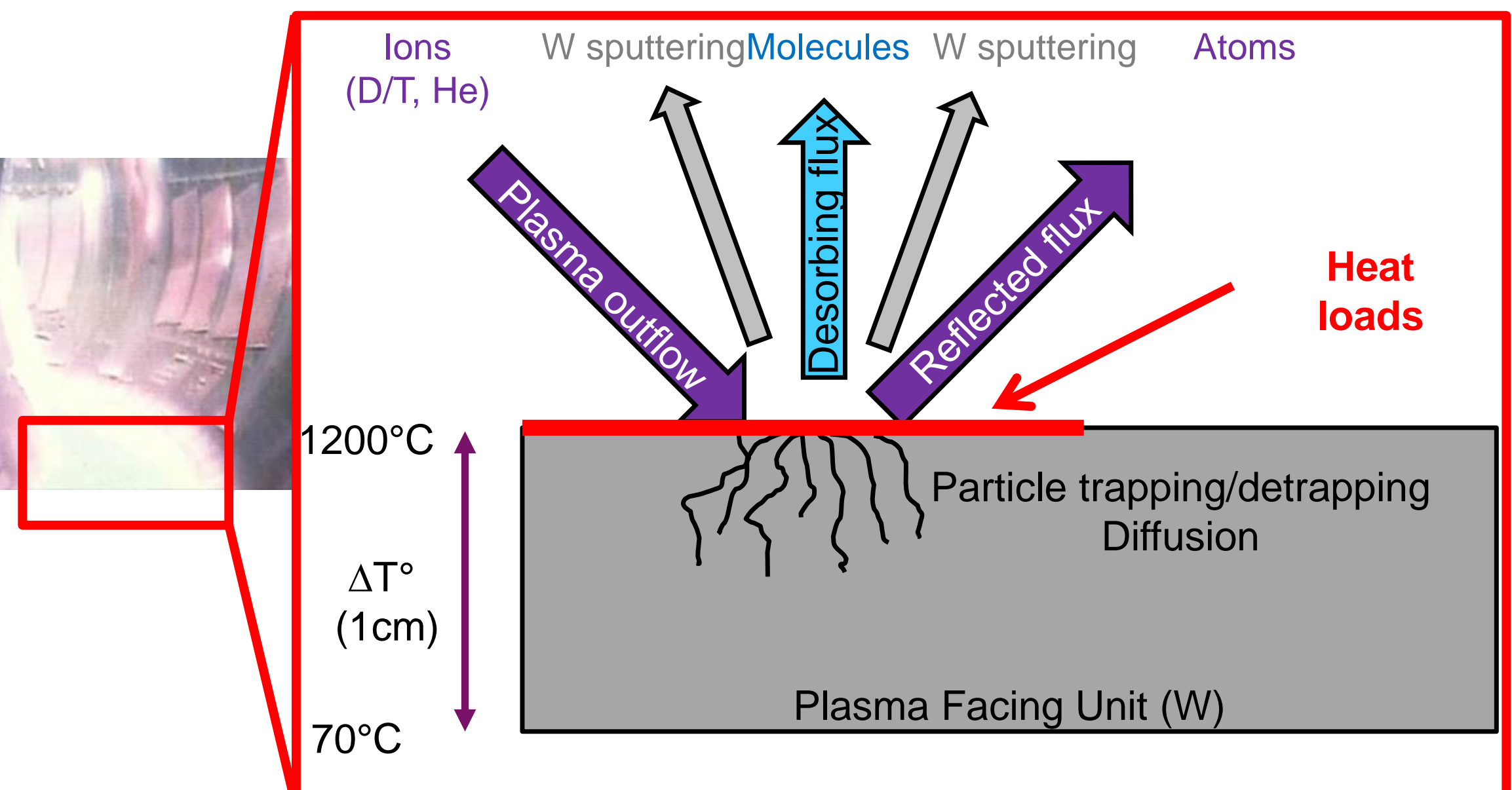




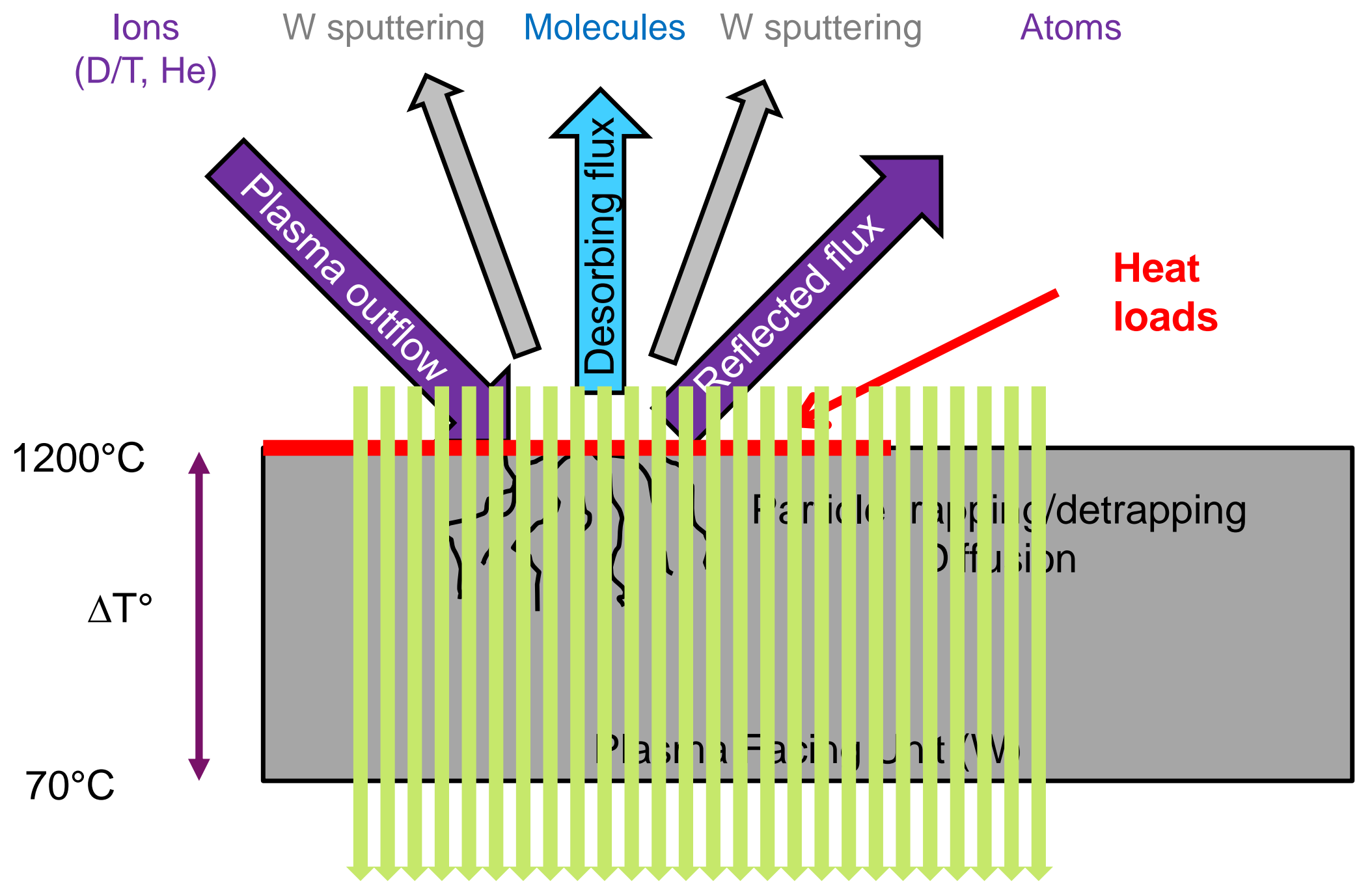

Neutron irradiation (14 MeV) 


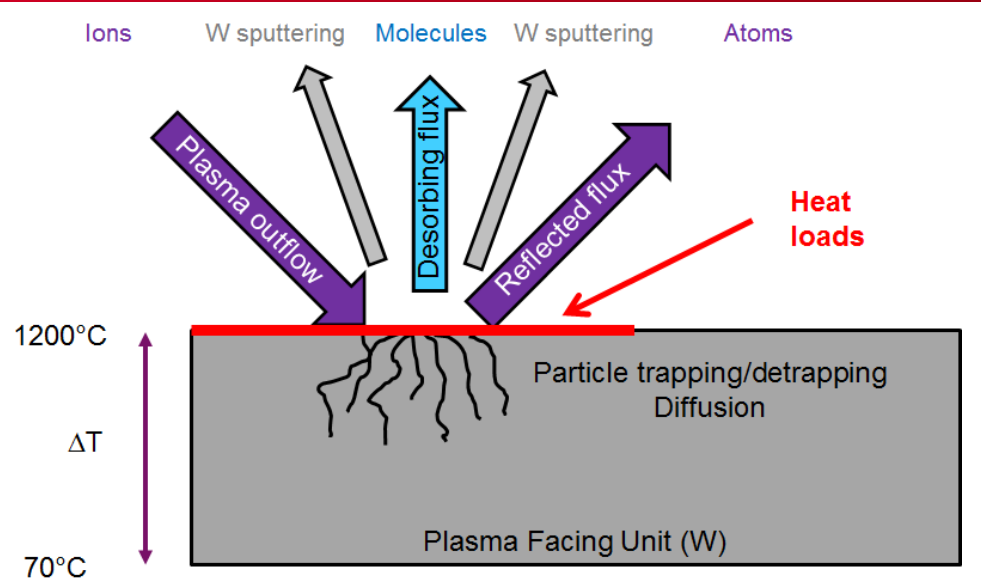

- Heat Loads and large $\Delta T^{\circ}$ : Well designed PFUs (steady sate operation)

- But problems of induced cracks etc...

- PWI on PFUs:

- W sputtering: pollution of the discharge (could prevent operation)

- Modification of the surface properties

- Creation of defects by plasma irradiation

- Particles trapping and diffusion:

- Helium bubbles

- Tritium/deuterium trapping

- Recycling flux (Reflected/Desorbing): control the plasma edge

- Neutrons irradiation:

- Helium bubbles

- Induced defects 


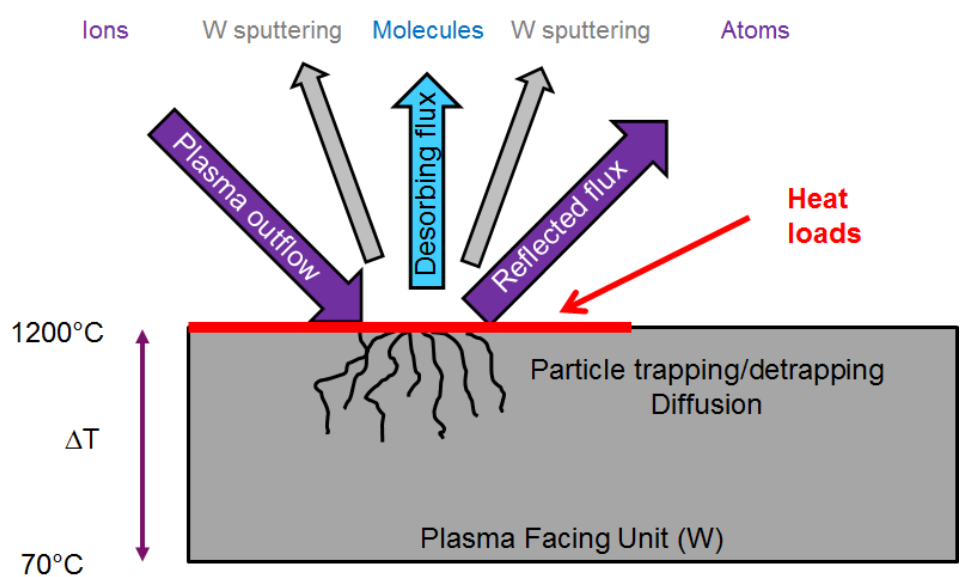

- Heat Loads and large $\Delta \mathrm{T}^{\circ}$ : Well designed PFUs (steady sate operation)

- But problems of induced cracks etc...

- PWI on PFUs:

- W sputtering: pollution of the discharge (could prevent operation)

- Modification of the surface properties

- Creation of defects by plasma irradiation

- Particles trapping and diffusion:

- Helium bubbles

Increase erosion,

- Tritium/deuterium trapping decrease heat conductivity (factor 100) Ageing of PFUs (diagnostic and control)

- Recycling flux (Reflected/Desorbing): control the plasma edge

- Neutrons irradiation:

- Helium bubbles

- Induced defects 


\section{(WEST: W Environment in Steady-state Tokamak)}

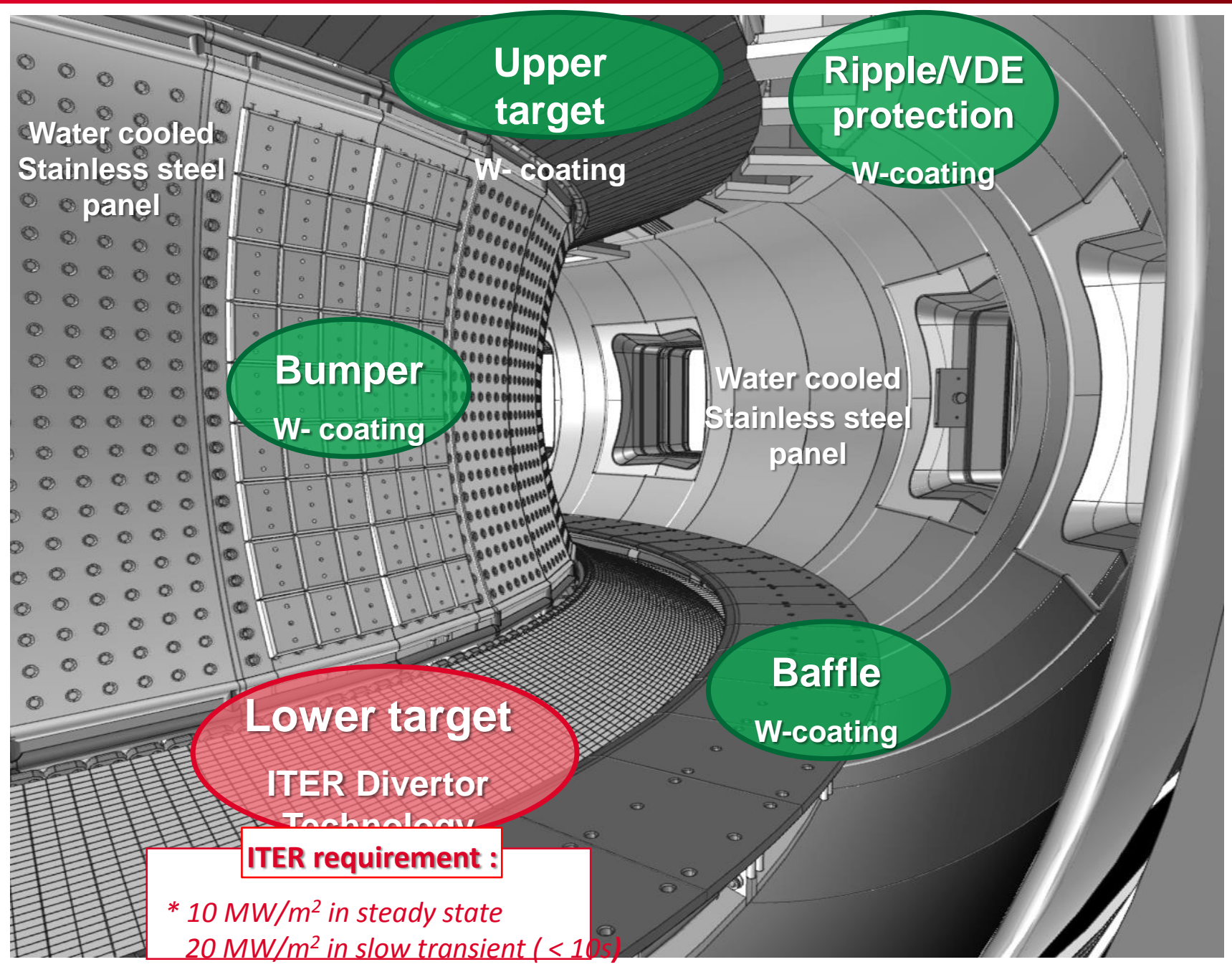

WEST: W, actively cooled PFU (ITER type), 


\section{(WEST: W Environment in Steady-state Tokamak)}

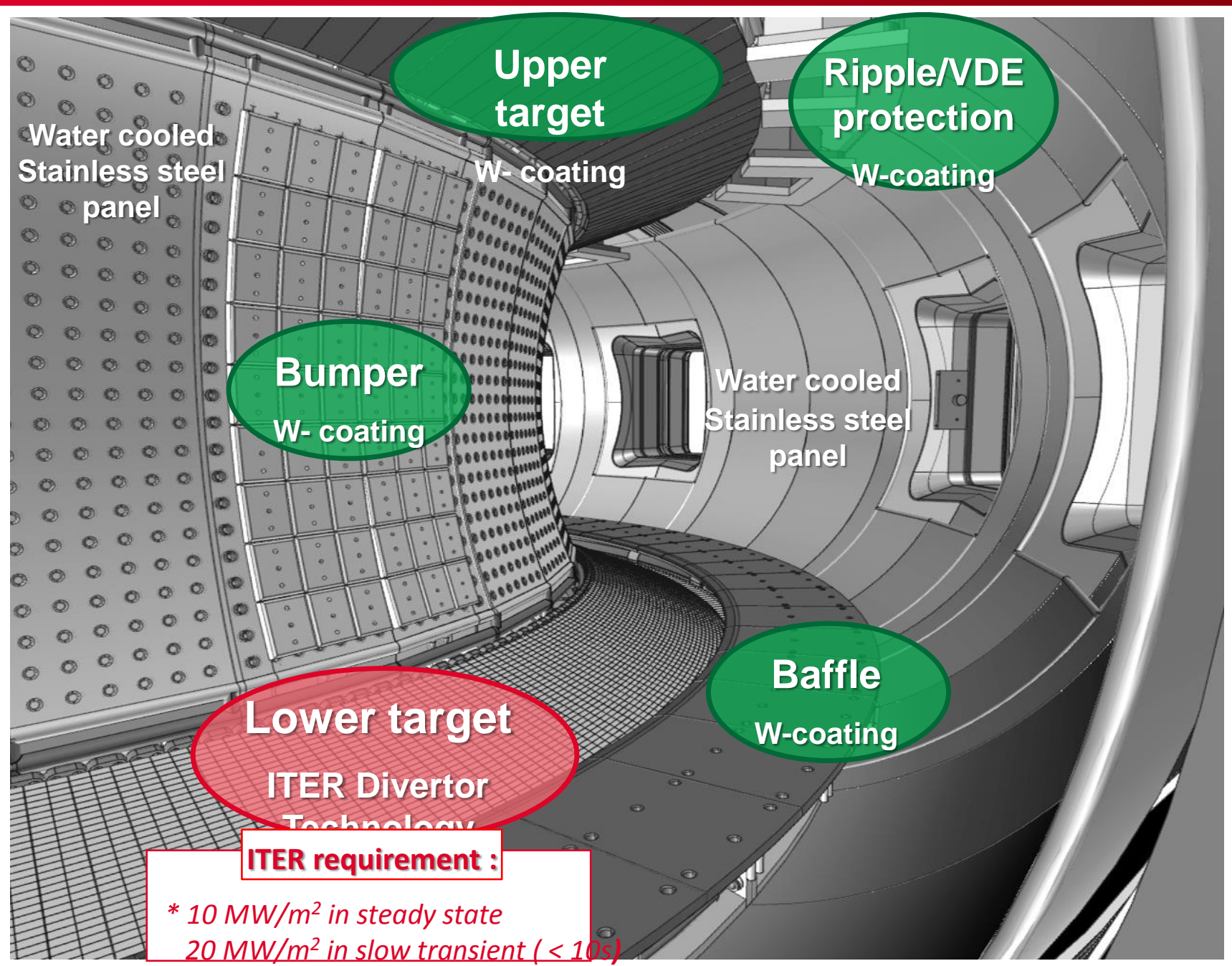

WEST: W, actively cooled PFU (ITER type), Test of the industrialization of the ITER W PFU (quality control, ....) 


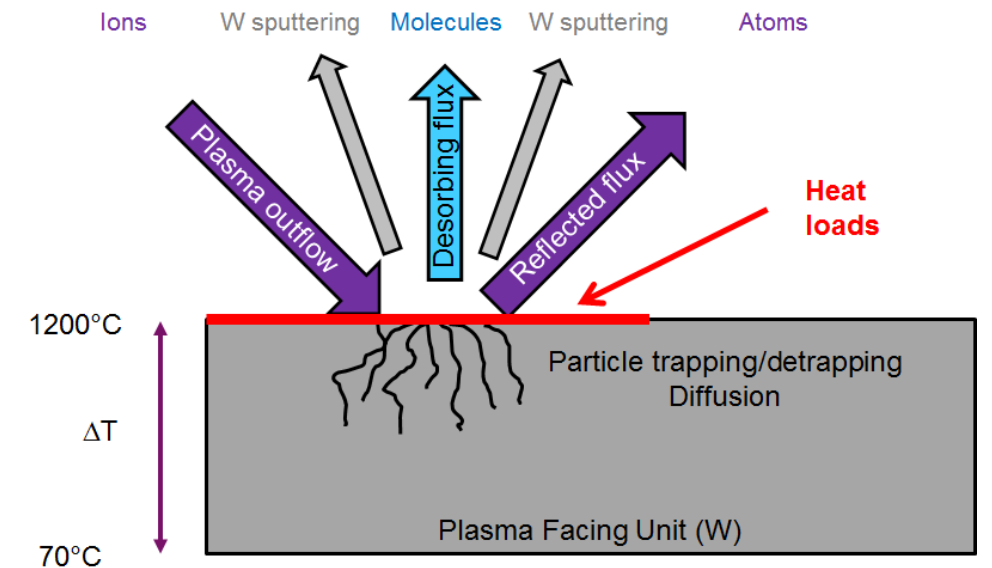

- Heat Loads and large $\Delta T^{\circ}$ : Well designed PFUs (steady sate operation)

- But problems of induced cracks etc...

- PWI on PFUs:

- W sputtering: pollution of the discharge (could prevent operation)

- Modification of the surface properties

- Creation of defects by plasma irradiation

- Particles trapping and diffusion:

Ageing of PFUs (diagnostic and control)

- Helium bubbles

Tritium/deuterium trapping

- Recycling flux (Reflected/Desorbing): control the plasma edge - Neutrons irfadiation:

- Helium bubbles

- Induced defocts 


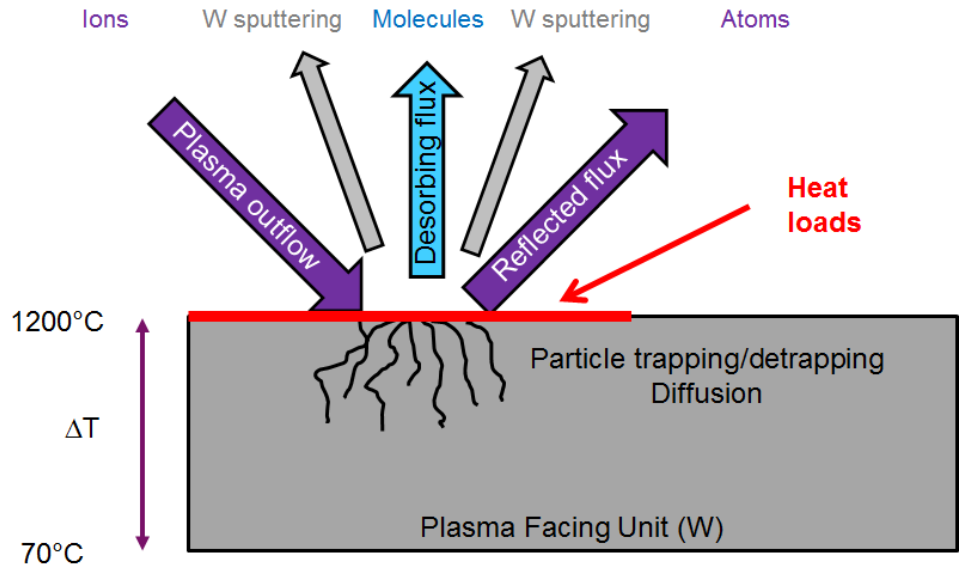

Major WEST objectives

- Heat Loads and large $\Delta T^{\circ}$ : Well designed PFUs (steady sate operation)

- But problems of induced cracks etc...

- PWI on PFUs:

- W sputtering: pollution of the discharge (could prevent operation)

- Modification of the surface properties

- Creation of defects by plasma irradiation

- Particles trapping and diffusion:

Ageing of PFUs (diagnostic and control)

- Helium bubbles

Tritium/deuterium trapping

- Recycling flux (Reflected/Desorbing): control the plasma edge

- Neutronsiradiation:

- Helium bubbles

- Induced defects 


\section{Plasma Wall Interaction in Tokamak (ITER): The WEST contribution}

- Heat Loads and large $\Delta \mathrm{T}^{\circ}$ : Well designed PFUs (steady sate operation)

- But problems of induced cracks etc...

- PWI on PFUs:

- W sputtering: pollution of the discharge (could prevent operation)

- Modification of the surface properties

- Creation of defects by plasma irradiation

- Particles trapping and diffusion:

Ageing of PFUs (diagnostic and control)

- Helium bubbles

- Tritium/deuterium trapping

- Recycling flux (Reflected/Desorbing): control the plasma edge

- Neutronsiradiation:

- Helium bubbles

- Induced defocts 


\section{W/H Interaction Studies in a Complete and Integrated approach}

Study and Model D/T implantation and trapping in W material (model, real):

- control of the plasma edge (desorbing flux)

- Trapping of $D$ (and $T$ ): safety issues

- Contributing to T permeation and to detritiation processes evaluation

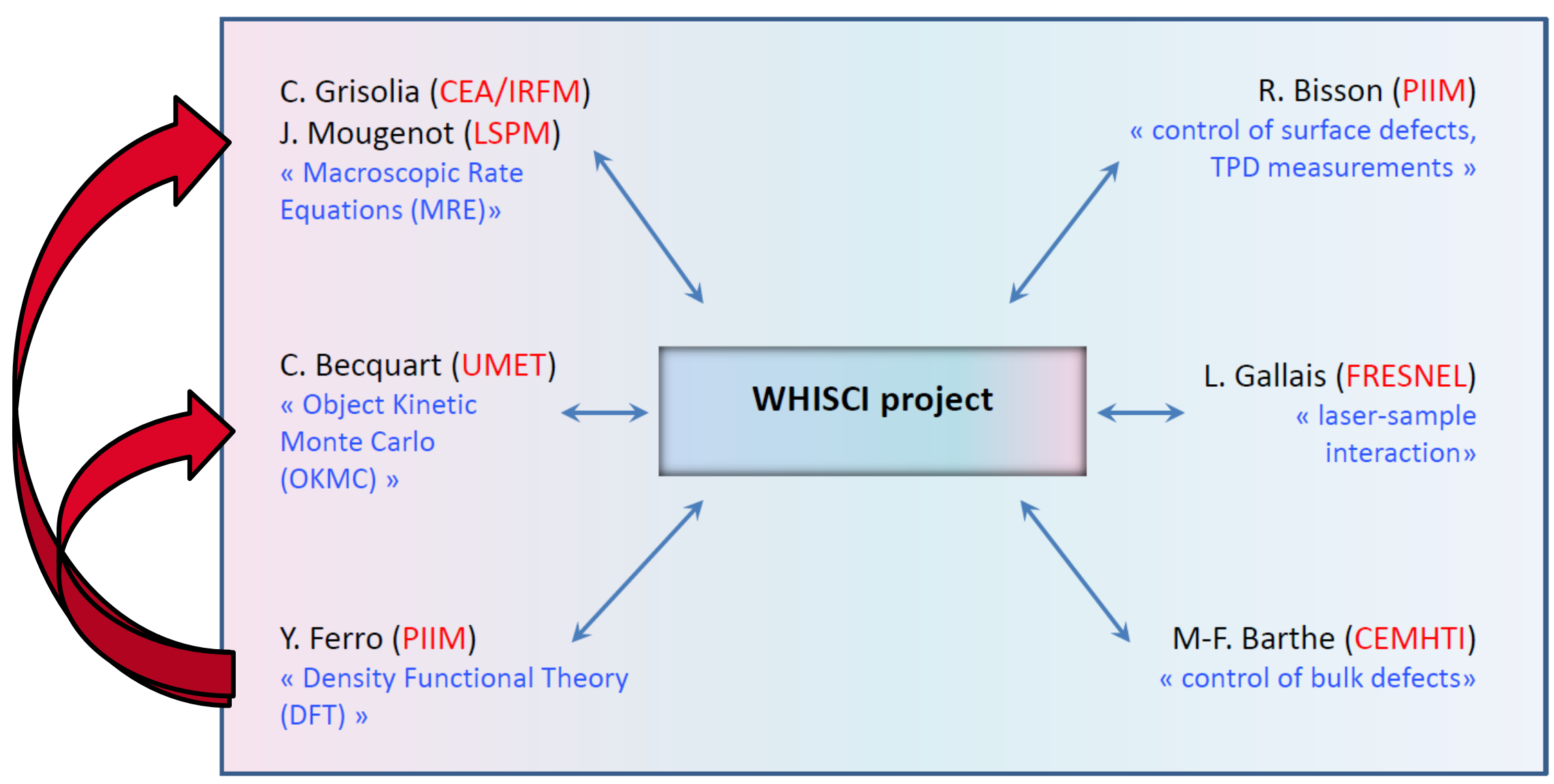

A*MIDEX project (AMU), Coordinator: R Bisson, PIIM laboratory 


\section{Macroscopic Rate Equation model}

\section{MRE 1D modeling}

$$
\begin{aligned}
& \frac{\partial C_{t, i}}{\partial t}=-C_{t, i} \cdot v_{i}(T)+v_{m}(T) \cdot C_{m} \cdot\left(1-\frac{C_{t, i}}{n_{i}}\right) \\
& \frac{\partial C_{m}}{\partial t}=\mathrm{D}(T) \cdot \frac{\partial^{2} C_{m}}{\partial x^{2}}-\sum \frac{\partial C_{t, i}}{\partial t}+S_{\text {ext }}
\end{aligned}
$$

trapped particles

mobile particles

\section{- Classic approach}

- developed to fit experimental data coming from W polycrystal experimental studies

- Used to check parameters, ... without any link with physical processes (an "engineer" approach) 


\section{Macroscopic Rate Equation model}

trapped particles

$$
\begin{aligned}
& \frac{\partial C_{t, i}}{\partial t}=-C_{t, i} \cdot v_{i}(T)+v_{m}(T) \cdot C_{m} \cdot\left(1-\frac{C_{t, i}}{n_{i}}\right) \\
& \frac{\partial C_{m}}{\partial t}=\mathrm{D}(T) \cdot \frac{\partial^{2} C_{m}}{\partial x^{2}}-\sum \frac{\partial C_{t, i}}{\partial t}+S_{\text {ext }}
\end{aligned}
$$

mobile particles

D implantation and Thermo-Desorption

\section{Parameters}

- W

- $E_{\text {imp }}=200 \mathrm{eV} / \mathrm{D}$

- $\Phi=2,510^{19} \mathrm{D} / \mathrm{m}^{2} / \mathrm{s}$, Fluence $=10^{22} \mathrm{D} / \mathrm{m}^{2}$

- $\mathrm{T}_{\text {imp }}=300 \mathrm{~K}$

- TDS ramp up $=8 \mathrm{~K} / \mathrm{s}$

Trap 1: $\mathrm{E}_{\mathrm{T} 1}=0.87 \mathrm{eV}, \mathrm{n}_{1}=110^{-3}$

Trap 2: $\mathrm{E}_{\mathrm{T} 2}=1.00 \mathrm{eV}, \mathrm{n}_{2}=410^{-4}$

Trap 3: $\mathrm{E}_{\mathrm{T} 3}=1.50 \mathrm{eV}, \mathrm{n}_{3}=210^{-2}$

$\left(\mathrm{n}_{\mathrm{i}}\right.$ trap concentration in at. 1

(E Hodille, CEA/IRFM)

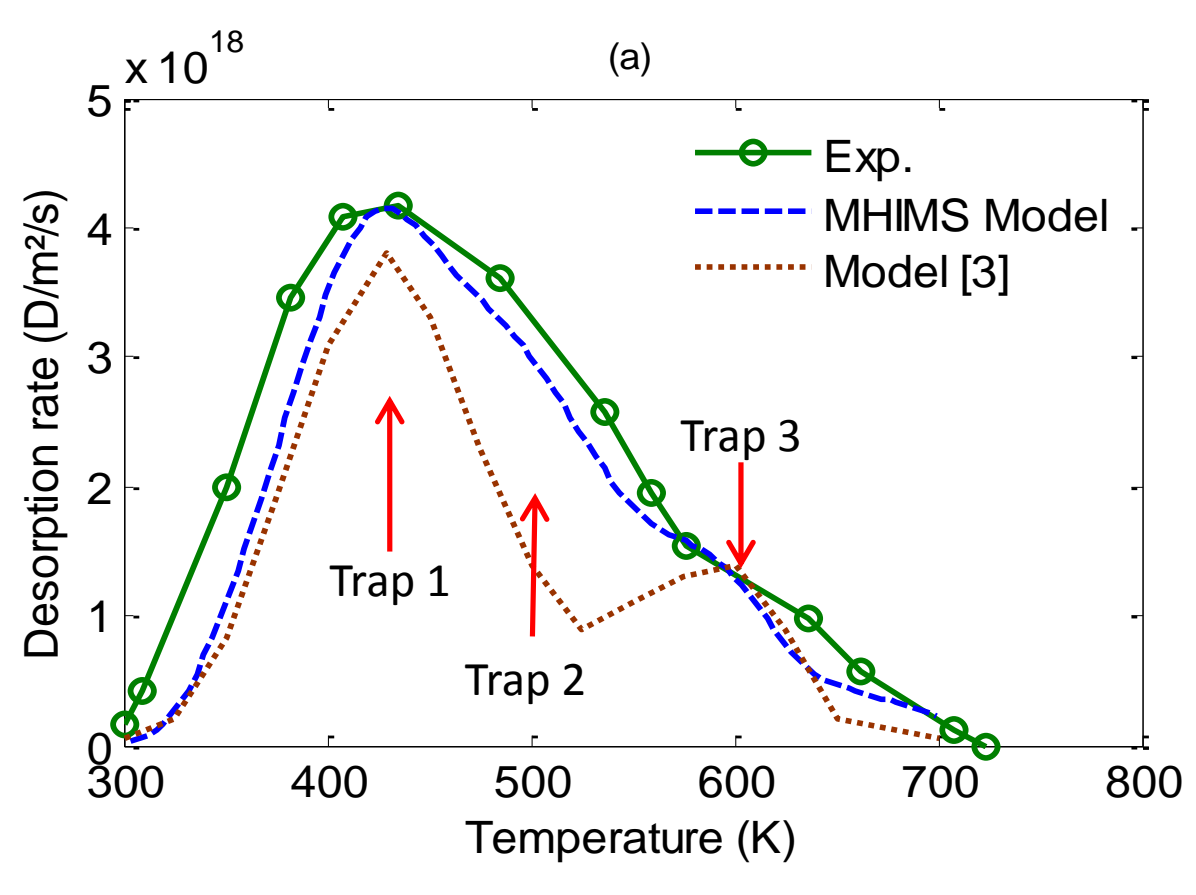




\title{
MRE 1D modeling
}

$$
\begin{aligned}
& \frac{\partial C_{t, i}}{\partial t}=-C_{t, i} \cdot v_{i}(T)+v_{m}(T) \cdot C_{m} \cdot\left(1-\frac{C_{t, i}}{n_{i}}\right) \\
& \frac{\partial C_{m}}{\partial t}=\mathrm{D}(T) \cdot \frac{\partial^{2} C_{m}}{\partial x^{2}}-\sum \frac{\partial C_{t, i}}{\partial t}+S_{\text {ext }}
\end{aligned}
$$

trapped particles

mobile particles

\section{Each trap contains only one Hls}

\author{
Different from DFT outcomes: \\ One vacancy can contain at RT up to $6 \mathrm{HIs}$
}

(Density Functional Theory (DFT) results from N Fernandez \& Y Ferro, PIIM Lab, Marseille) 


\section{New approach of Macroscopic Rate model}

\section{Formalism:}

One single trap in W contains up to $\mathrm{n}$ Hls ( $\mathrm{n}=6$ at $\mathrm{RT}$ )

Binding energy function of $\mathrm{i}$ (filling of trap)

\section{Mechanisms:}

A i-trap containing i Hls can be changed into:

- i+1-trap by trapping a solute particle

- i-1-trap by detrapping a particle

Solute population is governed by usual diffusion equation

(including detrapping effects and implantation due to incoming $D$ flux)

\section{Boundary conditions:}

Desorption not limited by surface recombination

No trap creation

Implantation and TDS simulated

MHIMS-reservoir

(Migration of Hydrogen Isotopes in MetalS)

"Study of a multi trapping macroscopic rate equation model for hydrogen isotopes in tungsten materials",

E Hodille et al, accepted for publication, Physica Scripta, 2015 


\section{Parameters used in the simulation}

fluence $=10^{23} \mathrm{D} / \mathrm{m}^{2}$, flux $=10^{20} \mathrm{D} / \mathrm{m}^{2} / \mathrm{s}, 500 \mathrm{eV} / \mathrm{D}$, heating ramp $=5,5 \mathrm{~K} / \mathrm{s}$

1 type of trap (vacancy) with $n=6$ filling capability $(R T)$

(a)

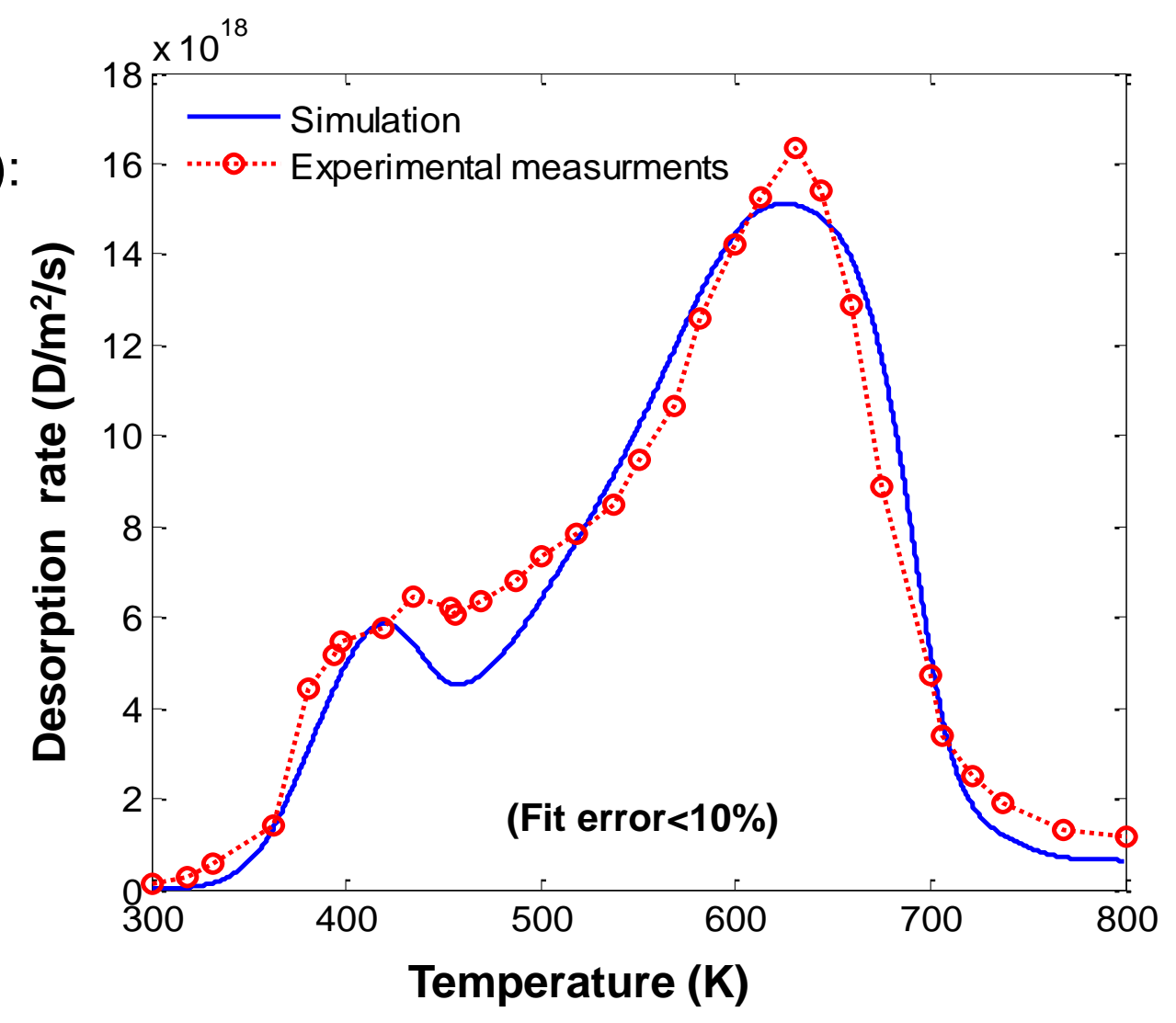




\section{Object Kinetic Monte Carlo versus MRE: Modeling Thermo-desorption}

Comparison between OKMC (LAKIMOCA) and MHIMS-reservoirs, based on DFT results

Conditions:

- Sample of $300 \mathrm{~nm}$ ( $1000 \mathrm{~W}$ cells)

- Vacancies density: $210^{-6}$

- At RT, vacancies filled by $6 \mathrm{H}$

- Tramp up: $1 \mathrm{~K} / \mathrm{s}$

- TDS starts immediately:

- 3 peaks observed

- TDS starts after 1000 s at $300 \mathrm{~K}$ :

- Disappearance of low temperature band

\section{Perfect agreement}

(LAKIMOCA, C Becquart, UMET, Lille MHIMS-reservoir, E Hodille, CEA/IRFM)
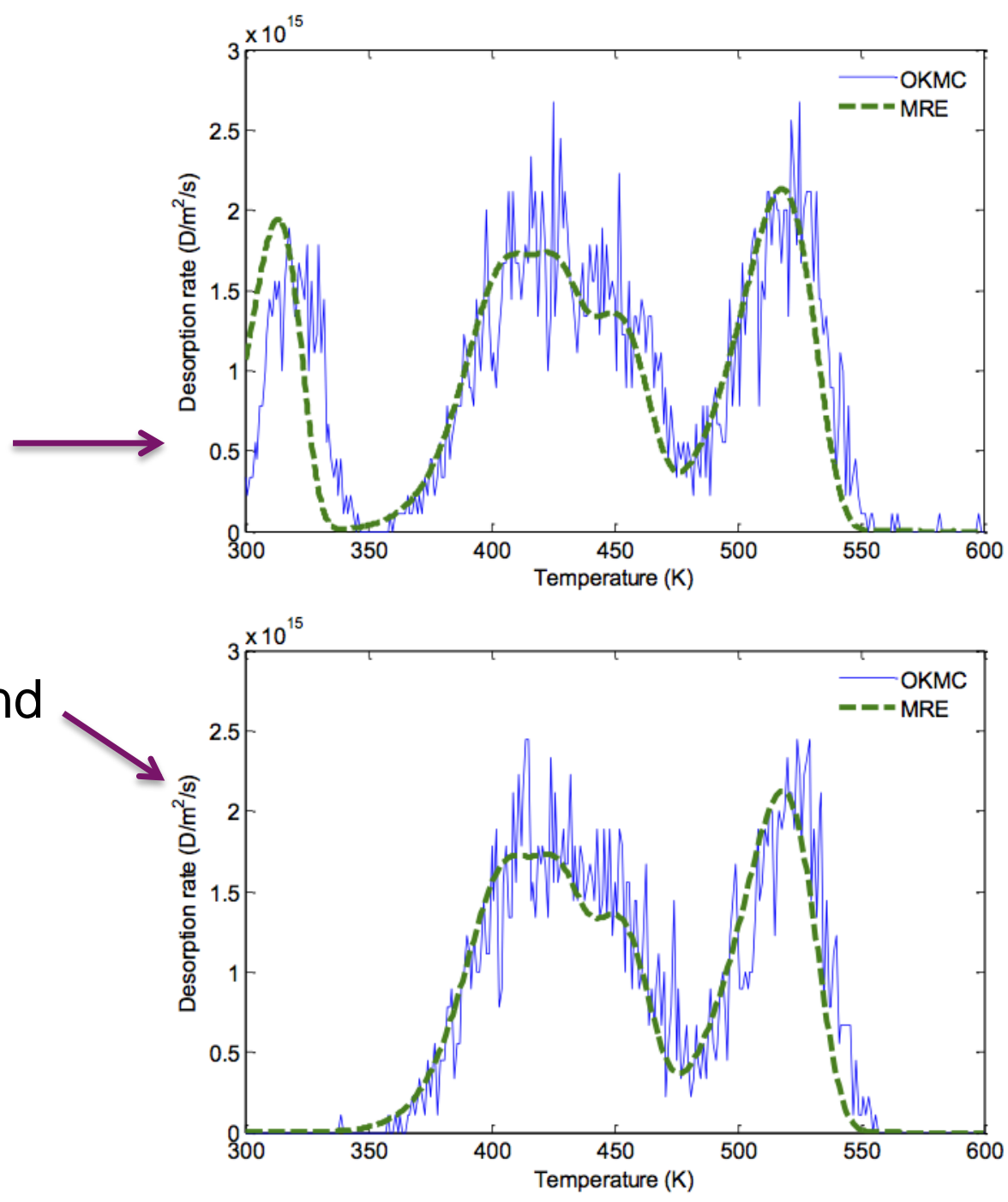


\section{MHIMS reservoir with a trap creation process}

Creation of vacancies driven by the solute particles concentration (Y Ferro, PIIM)

Where :

Dynamic of the evolution of the vacancies is introduced by

$$
\frac{\partial N_{v a c}}{\partial t}=f\left(C_{m}, T\right)=v_{c r e a} \cdot C_{m}-v_{a n n i} \cdot N_{v a c}
$$

$\square v_{\text {crea }}\left(\mathrm{s}^{-1}\right)$ :

$\checkmark v_{\text {anni }}\left(\mathrm{s}^{-1}\right):$

$$
\begin{aligned}
& v_{\text {crea }}=v_{0} \cdot e^{-\frac{E_{\text {crea }}\left(C_{m}\right)}{k \cdot T}} \text { where } \mathrm{E}_{\text {crea }} \text { the creation energy } \\
& v_{\text {anni }}=v_{0} \cdot e^{-\frac{E_{\text {anni }}\left(N_{\text {vac }}\right)}{k \cdot T}} \text { where } \mathrm{E}_{\text {anni }} \text { the annihilation energy }
\end{aligned}
$$

Trapping energies from DFT calculation

This approach is flux dependent and it is crosschecked with available experimental results

All experimental processes simulated: implantation, TDS and waiting time between both 


\section{MHIMS reservoir with a trap creation process: crosschecked with experimental data}

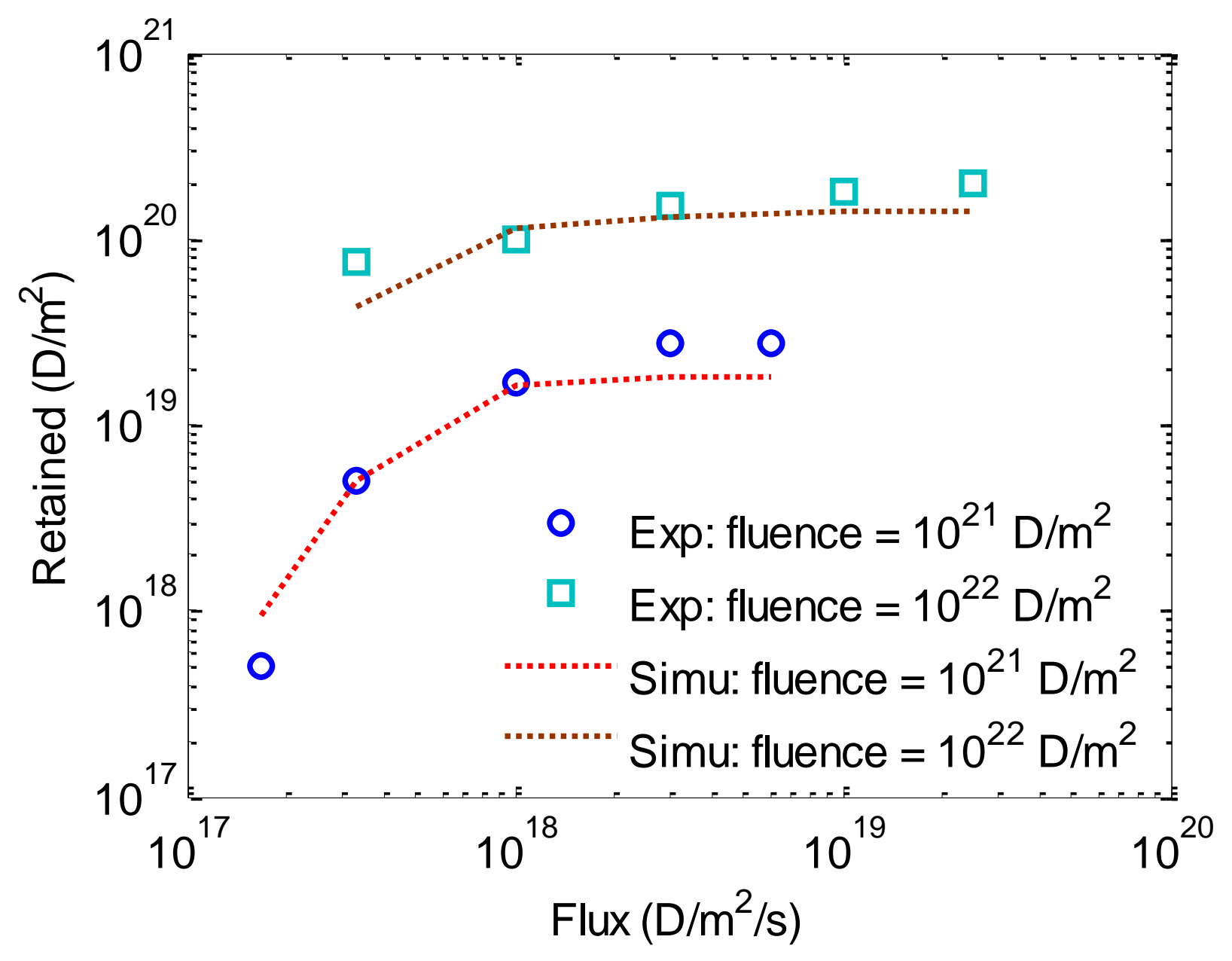

$v_{c r e a}$ and $v_{a n n i}$ complex functions: not really satisfying (Work in progress) 


\section{WHISCI near future}

- Model (W SC, non damaged W PC) material almost addressed (experimentally and model)

- Work in progress towards real life materials:

- Damaged WSC and WPC (by high energy W ions or electrons)

- Oxide layers 


\section{What to take away...}

- The WEST tokamak will operate in 2016;

- This is the only W actively cooled machine (other as EAST use B coated W)

- Able to operate in long pulse configuration

- Different ITER material open issues tackled in WEST:

- Test of ITER PFUs in real tokamak environment up to $10-20 \mathrm{MW} / \mathrm{m}^{2}$

- Assessment of PFUs ageing under high heat and plasma outflow

- Creation of defects under plasma irradiation

- Creation of He bubbles

- Creation of blisters (if any observed)

+ associated modelling

- Development of related diagnostics for PFUs integrity and ageing control

- Samples will be available during the life of WEST for material analysis and strong contribution to all these topics

- All studies undertaken in strong interaction with a large worldwide network of collaborations (WEST as a scientific and technological platform)

- Including a strong support of Aix Marseille University via initiative excellence $A^{*}$ MIDEX (supporting 5 fusion projects, AMU-IRFM)

- Tritium studies undertaken in parallel at the Saclay Tritium Lab.

- Linked with ITER safety and detritiation open issues

- Able to complement the WEST contribution 


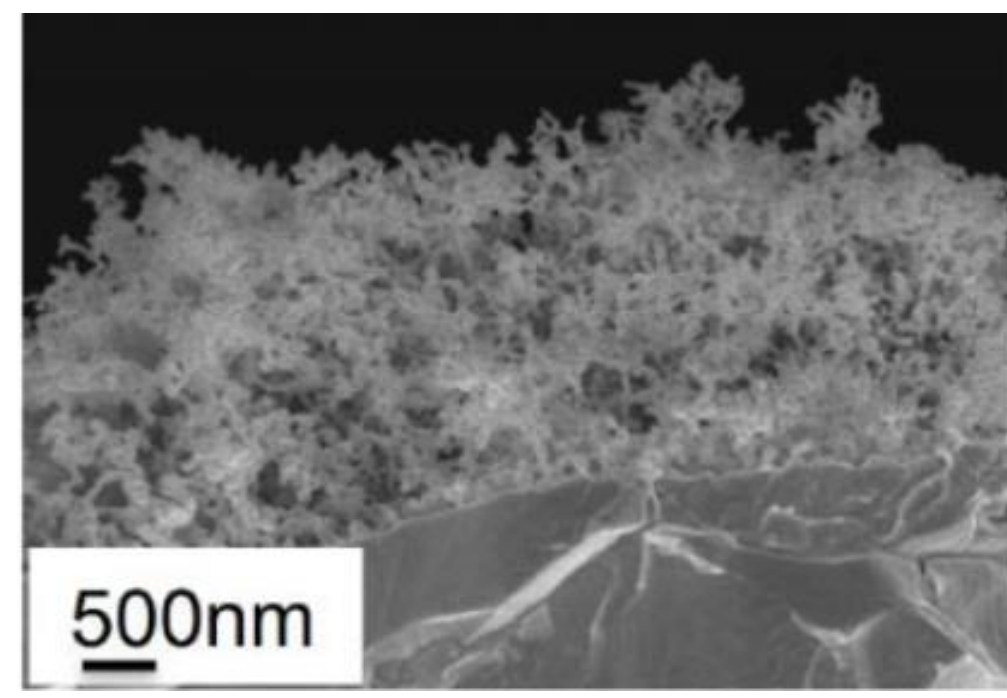

He fuzz formation
- He, Tsurf $>700^{\circ} \mathrm{C}$,
flux $>10^{21} \mathrm{~m}^{-2} \mathrm{~s}^{-1}$
fluence $>10^{25} / \mathrm{m}^{2}$
Energy $>20 \mathrm{eV}$

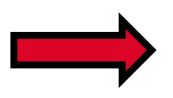


High temperature helium irradiation of tungsten: multi technique defect characterization and additional $H$ trapping R. Sakamoto ${ }^{a}$, E. Bernard ${ }^{b}$, N. Yoshidac, E. Hodilled, C. Grisolia ${ }^{d}$

LHD, NIFS He Plasma
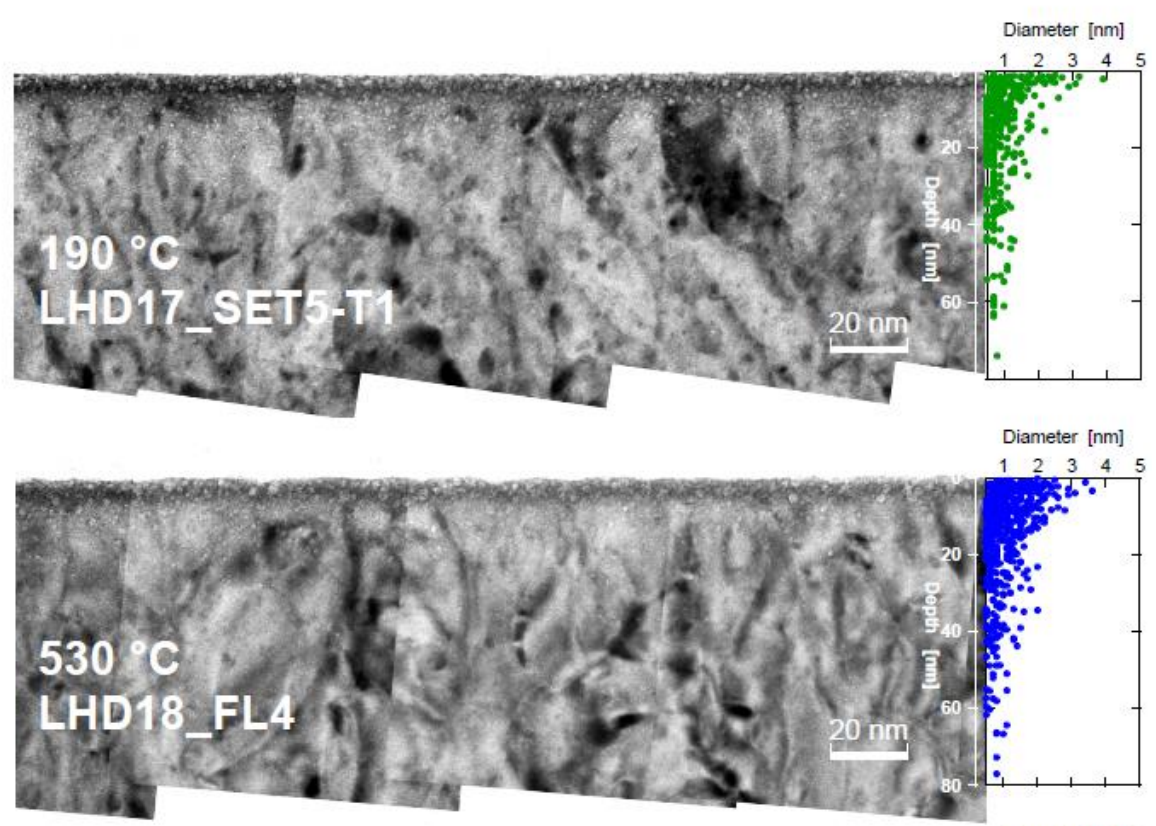

Diameter $[\mathrm{nm}]$

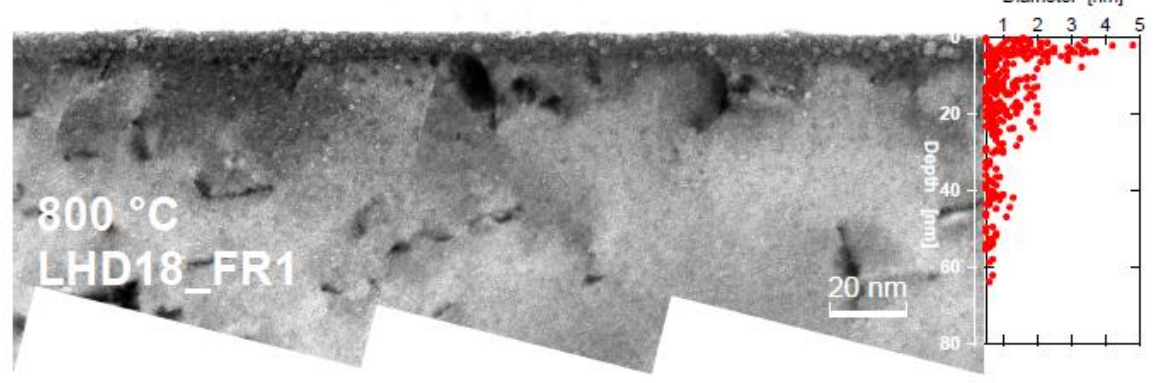

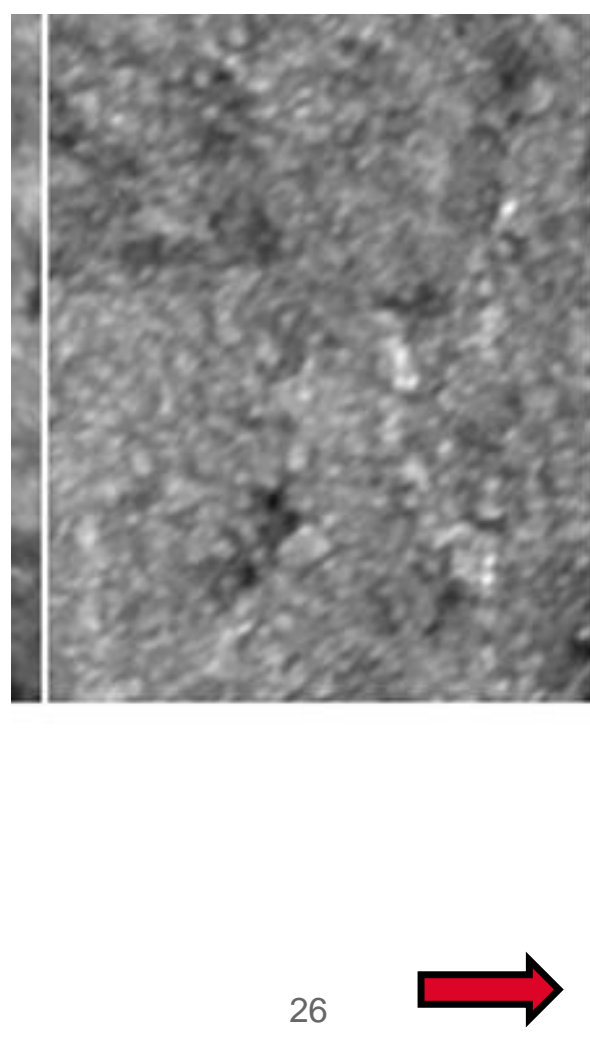

